\title{
Curability and Relapse in Leprosy.
}

Kensuke Mitsuda.

INTRODUCTION.

$\mathrm{D}^{\mathrm{n}}$ R. COCHRANE asked me to comment upon Dr. Rose's work, "The Curability of Leprosy." Owing to the delay in the arrival of his letter, and also to the confusion occasioned by the severe tidal wave at Osaka, which swept away Sotojima Leprosarium, resulting in the death of one hundred and seventy of the inmates, this contribution has been delayed.*

\section{How to Discuss "Curability."}

First of all, we must understand correctly the classification of leprosy before discussing its curability. Many workers have been misled owing to insufficient understanding of the classification of leprosy. The Manila Conference classified leprosy as neural and cutaneous. Neural consists of the macular type (we include maculotuberculoid) and neural type, while cutaneous signifies the nodular type of previous classifications. $\dagger$ Usually leprosy, as seen in Japan, begins in the macular type and advances to the more serious stage of neural leprosy, and some years later it passes into the cutaneous, nodular type.

* We hope to give further details of this very regrettable catastrophe at a later date. - Editor.

$\dagger$ The Manila classification of cutaneous leprosy included " all cases showing leprotic lesions in the skin" and therefore was not confined solely to the nodular tvoe.-Editor. 
Of course, there are many varieties; some neural cases remain as the neural type throughout life, and some pass into the cutaneous type several months after the appearance of macules or anæsthetic patches, but generally these two stages-neural and cutaneous-are consecutive. It would be irrational to endeavour to compare the prognosis of syphilis in the primary stage (chancre) with that, say, of syphilis in the tertiary stage (gumma), and therefore the endeavour to compare the prognosis of leprosy in the neural and cutaneous stages is, I hold, equally irrational. It is because of this attempt to do so that the problem of curability has become so very confused.

Curability of the Neural Type.

Strange to say, there have been scarcely any reports about the curability of neural cases. Of course, there are a number of such reports, but for definite conclusions to be arrived at, prolonged observations are necessary. It is generally known that the macules tend to disappear with or without treatment, but such cases are seldom followed up over a period of ten years. For a discussion on the true prognosis of the initial neural case, it is necessary to observe continuously at least one hundred cases over a period of ten or twenty years. As leprosy is one of the most chronic of diseases, it would be over hasty to discuss its prognosis after only observing cases for three or four years.

Dr. Y. Hayashi once examined the initial symptoms of 1,284 leprous inmates in Zensei Hospital (265 neural and 1,019 cutaneous) and found that only $5.7 \%$ (7.1\% of cutaneous cases) had cutaneous symptoms (nodules, infiltration, depilation of eyebrows) as the initial symptom. In other words, in $92.9 \%$ of all the patients the initial symptoms were neural. The question that needs consideration is what percentage of neural cases remain cured in the neural stage without any further symptoms except residual anæsthetic patches, and what percentage advance into the severe neural type, or pass into the cutaneous type. Such a report should extend over a period of at least ten years. It is the duty of doctors in charge of out-patient clinics to study the future and the prognosis of the initial neural cases after long observation. We may classify the results in primary initial neural cases as follows :-

(1) Those resulting in cure without relapse.

(2) Those which advance to the severe neural type.

(3) Those which pass into the cutaneous type.

We, indeed, know some cases in the first category, but do not know how many of these remain in this initial stage. 


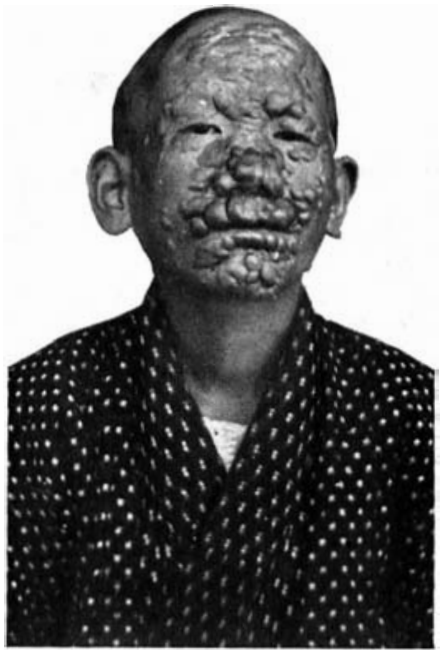

1. On admission.

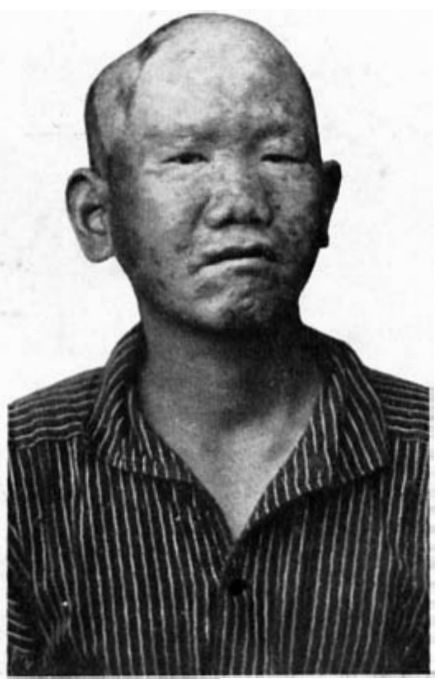

2. After 3 years' treatment.

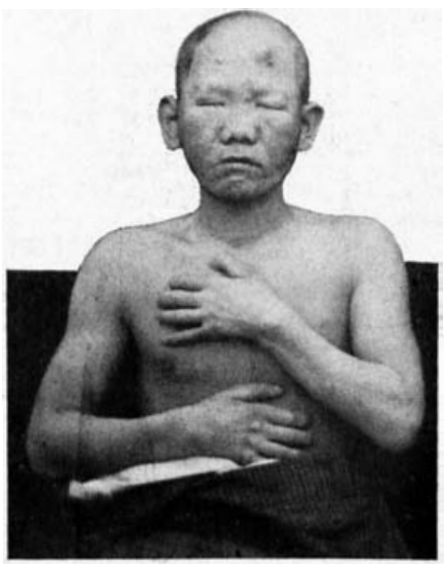

3. IBlind and Relapsed. 5 years later.

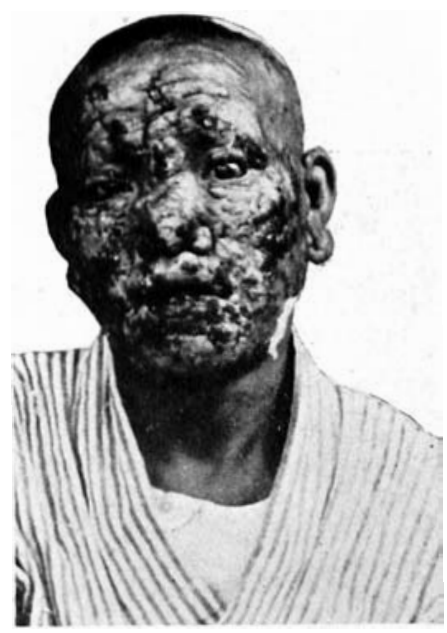

1. On admission.

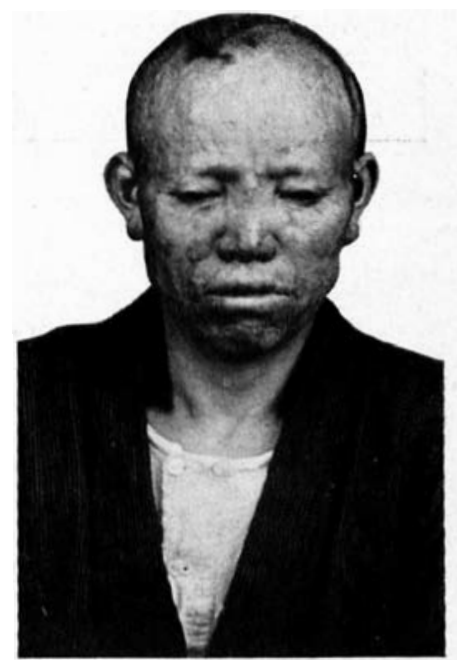

2. After 11 years' treaiment.

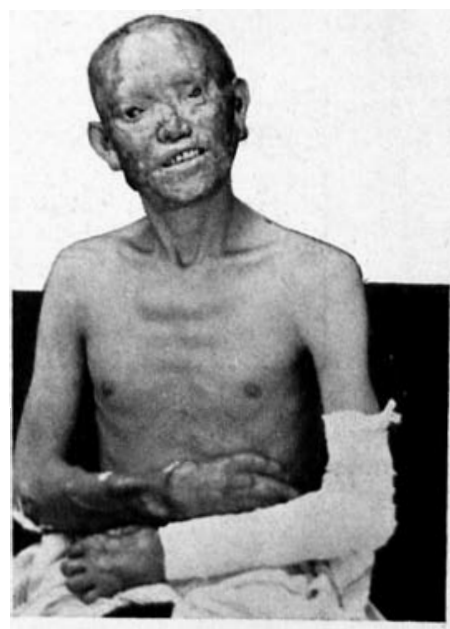

3. Relapsed. 5 years later. 


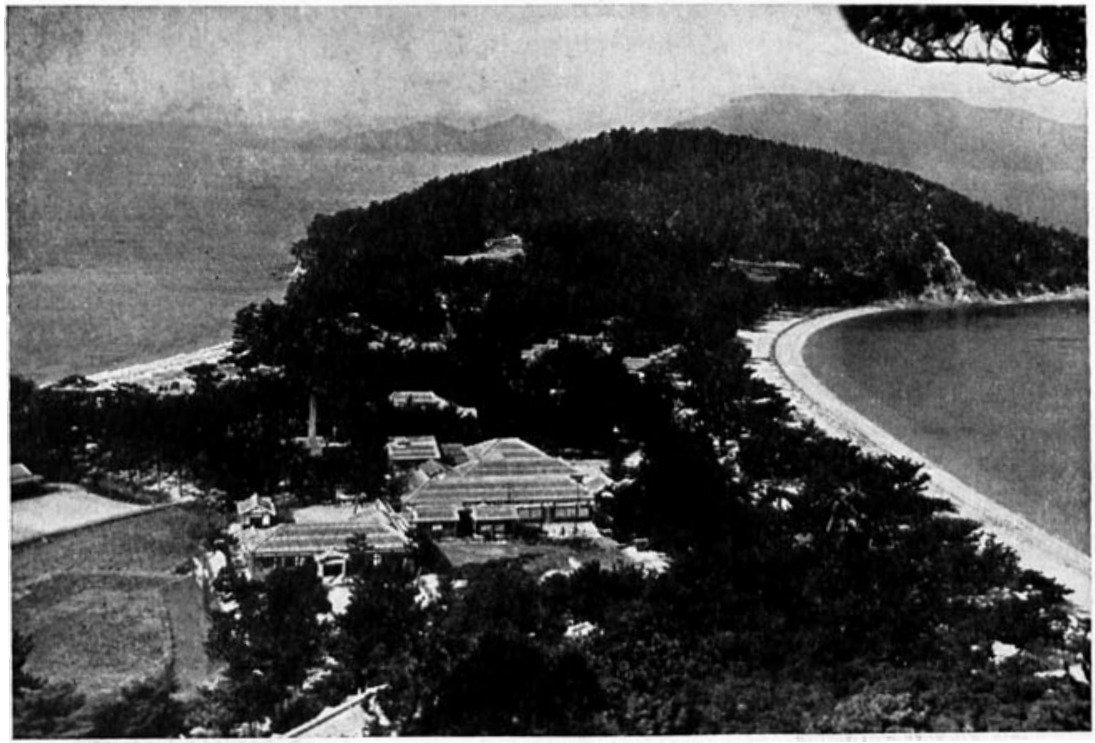

The Government I.eprosy Asylum on the Island of Shikoku, near Oshima, Japan.

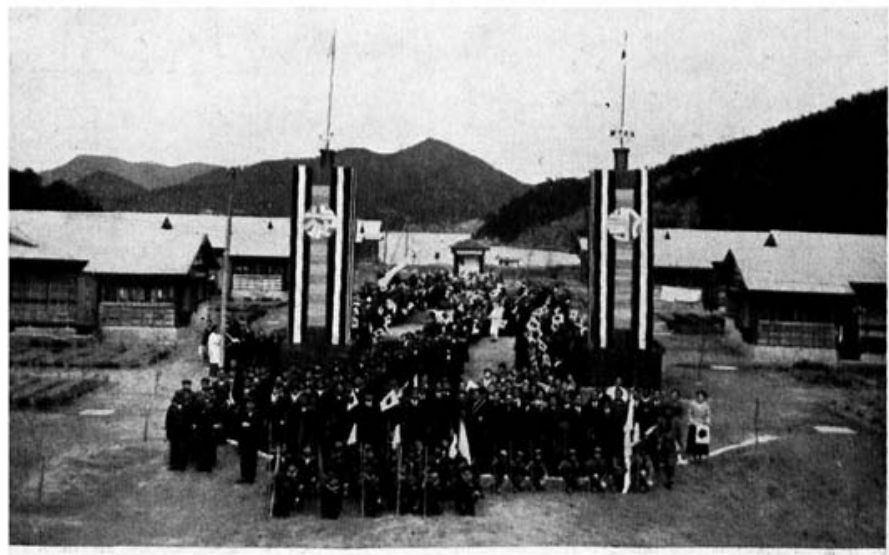

Dr. Fumio Hayashi welcomed back to Aiseien National Leprosarium, Okayama. 
Curability ani) Relapse in the Cutaneous Type.

It is the cutaneous case which has been under discussion so frequently and by many workers. The theme of Dr. Rose's article related to the cutaneous type. Dr. Y. Hayashi has shown certain statistics on this subject. Dr. Hayashi has devoted seventeen years to the study of the problem in the Zensei Hospital, and was appointed Director there after my transfer to Aiseien. (F. Hayashi, a namesake, travelled round the world last year.)

Quoting his work, there were 850 inmates in Zensei Hospital in 1929, and out of this number 662 were cutaneous cases. Among them there were 128 advanced cutaneous male cases, who had at one time been considered in a stage of cure.

Duration of apparent

$\begin{array}{lllllllllllllllll}\text { recovery (in years) } & 2 & 3 & 4 & 5 & 6 & 7 & 8 & 9 & 10 & 11 & 12 & 13 & 14 & 15 & 16 & 18\end{array}$ $\begin{array}{llllllllllllllllllll}\text { Number } & \ldots & \ldots & 10 & 16 & 14 & 20 & 13 & 12 & 10 & 2 & 14 & 1 & 6 & 4 & 2 & 2 & 1 & 1\end{array}$

The average number of years freedom from the disease was 6.5 years and then relapse followed. Among these, 13 patients experienced recovery twice, and the second relapse took place on an average of 4.5 years afterwards. These statistics were compiled from data concerning relapsed cases, therefore it is impossible to say that every case takes this course. We may classify the results in cutaneous cases as follows :-

(1) Relapsed cases.

(2) Cutaneous cases which show almost no improvement with treatment.

(3) Recovered or recovering cases :

(a) Those who will relapse in the future.

(b) Those who suffer no relapse during lifetime.

The first group has been discussed already, and the second is not pertinent to this article and therefore the third group alone remains.

Improvement in leprosy in most of the cutaneous cases with, or sometimes without, treatment, is common, but the question is how many have no relapse during life. After a long experience I can say that only $0.5 \%$, or at the most under $1 \%$ of cutaneous cases autopsied had no tendency or possibility of relapse in the future. For such a conclusion it needs at least $10-15$ years observation after the recovery of the patient. We must not confuse this relapse with that of neural cases. 


\section{Relapsed Cutaneous Cases.}

I enclose some photographs of typical relapsed cases. They all at one time passed through a recovered stage for 5-10 years before relapse. The second picture is after one or two years treatment in the hospital. Many readers will remember a photograph of an old Japanese man in the book " Leprosy," by Rogers and Muir (page 287) ; the case also relapsed with many nodules on the face and extremities after 10 years in the cured stage. He died in 1931.

\section{The General Course of Cutaneous Cases (in $70 \%$} TO $80 \%$ ).

I may also say that the leprolin test should be tried before discussing curability, prognosis and relapse. For this I would refer readers to an article by Dr. F. Hayashi, published in the International Journal of Leprosy, No. 1, January, 1933.

As I mentioned, prognosis in the neural and cutaneous stages are quite different, so it is necessary first to classify these two types exactly, and in this the leprolin test helps us greatly. They say that such and such a drug is very effective, that maculæ disappeared in several months with the treatment. But, in fact, generally most of the maculæ disappear in several months even without treatment. Curability of neural and cutaneous cases cannot be discussed together because each has a different prognosis. For this reason they are described separately.

\section{SUMMARY.}

In the article which appeared in LEPROSY REvIEw concerning the Curability of Leprosy, the author states that the reason for writing it is that some leprologists are optimistic concerning treatment, while others are equally pessimistic. These comments are written in an endeavour to emphasise as far as possible the facts as we have seen them. The first point stressed is that investigation should be made with regard to the percentage of neural cases which remain in a cured state throughout life.

Secondly, it is stated that $80 \%$ of cured cutaneous cases relapse, the remaining $20 \%$ include :-

(a) Patients with no recovery.

(b) Patients recovering, or recovered, who have had previous relapses and may have them in the future; and

(c) Those without relapse. 